Article

\title{
Characterizing the Physical Properties and Cell Compatibility of Phytoglycogen Extracted from Different Sweet Corn Varieties
}

\author{
Renjie Liu ${ }^{1}$, Susan K. Boehlein ${ }^{2}$, William F. Tracy ${ }^{3}{ }^{(}$, Marcio F. R. Resende Jr. ${ }^{2, *}$ and \\ Gregory A. Hudalla ${ }^{1, *(1)}$ \\ 1 J. Crayton Pruitt Family Department of Biomedical Engineering, Wertheim College of Engineering, \\ University of Florida, Gainesville, FL 32611, USA; renjieliu@ufl.edu \\ 2 Horticultural Sciences Department, University of Florida, Gainesville, FL 32611, USA; sboehlei@ufl.edu \\ 3 Department of Agronomy, University of Wisconsin-Madison, Madison, WI 53706, USA; wftracy@wisc.edu \\ * Correspondence: mresende@ufl.edu (M.F.R.R.J.); ghudalla@bme.ufl.edu (G.A.H.); Tel.: +1-352-273-4772 \\ (M.F.R.R.J.); +1-352-273-9326 (G.A.H.)
}

Academic Editor: Iva Pashkuleva

Received: 16 December 2019; Accepted: 31 January 2020; Published: 1 February 2020

check for updates

\begin{abstract}
Owing to its unique structure and properties, the glucose dendrimer phytoglycogen is gaining interest for medical and biotechnology applications. Although many maize variants are available from commercial and academic breeding programs, most applications rely on phytoglycogen extracted from the common maize variant, sugary1. Here we characterized the solubility, hydrodynamic diameter, water-binding properties, protein contaminant concentration, and cytotoxicity of phytoglycogens from different maize sources, A632su1, A619su1, Wesu7, and Ia453su1, harboring various sugary1 mutants. A619su1-SW phytoglycogen was cytotoxic while A632su1-SW phytoglycogen was not. A632su1-Pu phytoglycogen promoted cell growth, whereas extracts from A632su1-NE, A632su1-NC, and A632su1-CM were cytotoxic. Phytoglycogen extracted from Wesu7su1-NE using ethanol precipitation was cytotoxic. Acid-treatment improved Wesu7 phytoglycogen cytocompatibility. Protease-treated Wesu7 extracts promoted cell growth. Phytoglycogen extracted from Ia453su1 21 days after pollination ("Ia435su1 21DAP") was cytotoxic, whereas phytoglycogen extracted at 40 days ("Ia435su1 40DAP") was not. In general, size and solubility had no correlation with cytocompatibility, whereas protein contaminant concentration and water-binding properties did. A632su1-CM had the highest protein contamination among A632 mutants, consistent with its higher cytotoxicity. Likewise, Ia435su1 21DAP phytoglycogen had higher protein contamination than Ia435su1 40DAP. Conversely, protease-treated Wesu7 extracts had lower protein contamination than the other Wesu7 extracts. A632su1-NE, A632su1-NC, and A632su1-CM had similar water-binding properties which differed from those of A632su1-Pu and A632su1-SW. Likewise, water binding differed between Ia435su1 21DAP and Ia435su1 40DAP. Collectively, these data demonstrate that maize phytoglycogen extracts are not uniformly cytocompatible. Rather, maize variant, plant genotype, protein contaminants, and water-binding properties are determinants of phytoglycogen cytotoxicity.
\end{abstract}

Keywords: polysaccharide; phytoglycogen; cytocompatibility

\section{Introduction}

Polysaccharides, which are polymers of carbohydrates, are abundant throughout the natural world. They are found in algae, plants, microbes, bacteria, and animals [1,2]. Depending on their origin, polysaccharides can have unique chemical compositions [3,4], structures [5], and biological 
functions [6,7], such as cell adhesion [8-10], signaling [11,12], and activation [6,13-17]. Understanding the role of polysaccharides within living systems, and establishing methods to extract them, have enabled their increasing use as biomaterials $[18,19]$. For example, polysaccharides are employed as carriers for sustained drug delivery [20,21], scaffolds for tissue regeneration [22,23], and as protective agents for vaccines and pharmaceuticals [24-26]. Central to the success of polysaccharides in these applications is their biocompatibility and biodegradability [27].

Phytoglycogen is a glucose polysaccharide that is produced by plants [28]. Unlike starch, phytoglycogen is a dendritic macromolecule (Figure 1). The extensive branching of phytoglycogen results in unusually high solubility and low viscosity in water $[28,29]$. These features have led to an increasing interest in phytoglycogen for biomedical and biotechnology applications. For example, it can be used as a food additive [30,31], a vaccine adjuvant [32], an anti-oxidative reagent [33] and even as a natural moisturizer [34]. The most common source for phytoglycogen is the kernel of the maize mutant sugary1 (su1), a primary allele explored in commercial sweet corn production $[29,35]$. Phytoglycogen extracted from su1 mutants consists of glucose monomers connected by $\alpha-1,4$-glycosidic linkages, with branching on about every 13 monomer via an $\alpha-1,6$-glycosidic linkage $[28,36]$. Phytoglycogen dispersed in aqueous solutions shows a uniform spherical nanoparticle shape [37,38], and forms an opalescent colloidal dispersion [39]. The accumulation of phytoglycogen correlates with the deficiency of several debranching enzymes [40-42]. Plants contain two distinct types of starch debranching enzymes, the isoamylase type, and the pullulanase type. Isoamylases hydrolyze $\alpha-1,6$ linkages from amylopectin and glycogen, while pullulanase hydrolyzes the same bond in pullulan [43]. In maize, there are three isoamylases (ISA1, ISA2 and ISA3) and one pullulanase (PUL1). In maize, ISA1 is encoded by the sugary1 (su1) gene. There are currently five distinct naturally occurring mutations reported at the su1 locus. Three of these mutations are caused by single nucleotide polymorphisms (su1-NE, su1-NC, su1-SW), one has a $1.3 \mathrm{~kb}$ insertion (su1-CM), and one has an unknown genetic mutation that could not be identified within the coding sequence of the gene (su1-Pu) [44]. Immunoblots using the $\alpha$-isoamylase-type (ISA1) antibody indicate that su1-CM is a complete loss of function with no protein being produced. The other alleles form a protein, but enzyme activity cannot be detected in potato starch zymograms [45].

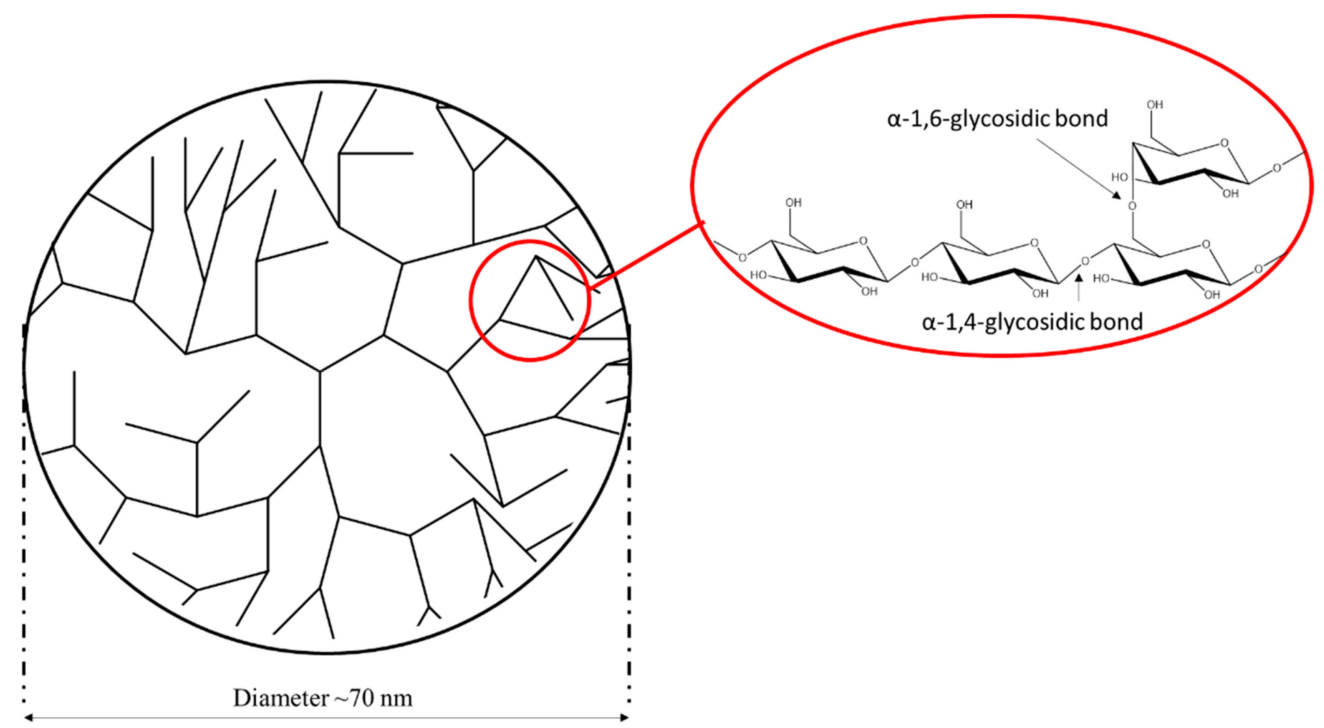

Figure 1. Schematic representation of the structure of phytoglycogen.

Although phytoglycogen cytotoxicity has been characterized before [32], these efforts have primarily involved the polysaccharide extracted from a sweet corn variant with the su1-NE allele, which is also known simply as su1 or su1-ref $[28,38,46]$. In the current study, we extracted and purified phytoglycogens from plants with various natural mutations of sugary1 in different sweet 
corn backgrounds using various methods. The cytotoxicity of these variants was characterized using an NIH3T3 fibroblast in vitro model. The influence of the source on the hydrodynamic diameter of phytoglycogen extracts was assessed using Dynamic Light Scattering (DLS). The interaction of water with phytoglycogen extracts from different sources was estimated using Fourier-transform infrared spectroscopy (FTIR). Lastly, the concentration of contaminating proteins in each phytoglycogen extract was measured using the bicinchoninic acid (BCA) assay. Collectively, these experiments identified relationships between cytotoxicity and the maize variant, the plant genotype, and the extraction methods, which will aid in future efforts to select phytoglycogen extracts that are suitable for use as biomaterials.

\section{Results and Discussion}

\subsection{Solubility of Phytoglycogen Extracts from Different Sources}

Phytoglycogen was extracted from the sweet corn varieties A632, A619, Wesu7, and Ia453 using either ethanol precipitation, ethanol precipitation with deproteinization, or ethanol precipitation with protease treatment. All phytoglycogen extracts were obtained as white powders and were suspended in $1 \times$ phosphate-buffered saline (PBS) at a concentration of $20 \mathrm{mg} / \mathrm{mL}$. We noted that all the solutions were milky, and when passed through a $0.22 \mu \mathrm{m}$ filter, the suspensions remained milky but with an increase in transparency. The concentration of phytoglycogen extract in each filtered suspension was determined by measuring the mass of powder obtained after lyophilization and subtracting the mass of lyophilized PBS vehicle (Table 1). The solubility of phytoglycogen variants ranged from $\sim 15$ to 20 $\mathrm{mg} / \mathrm{mL}$; however, no significant differences in solubility were observed between extracts with regard to plant variety, su1 allele, extraction method, or kernel maturity.

Table 1. Solubility of phytoglycogen extracts in $1 \times$ phosphate-buffered saline.

\begin{tabular}{ccc}
\hline Variants & Concentration $(\mathbf{m g} / \mathbf{m L})^{\text {a }}$ & Extraction Method \\
\hline A619su1-SW & $20.17 \pm 1.37$ & Ethanol precipitation \\
\hline A632su1-SW & $15.41 \pm 1.46$ & Ethanol precipitation \\
\hline A632su1-NC & $18.41 \pm 2.51$ & Ethanol precipitation \\
\hline A632su1-Pu & $17.18 \pm 3.28$ & Ethanol precipitation \\
\hline A632su1-NE & $19.56 \pm 2.8$ & Ethanol precipitation \\
\hline A632su1-CM & $18.01 \pm 3.18$ & Ethanol precipitation \\
\hline Wesu7-A (su1-NE) & $19.75 \pm 1.54$ & Ethanol precipitation \\
\hline Wesu7-B (su1-NE) & $20.41 \pm 0.54$ & Ethanol precipitation + deproteination \\
\hline Wesu7-C (su1-NE) & $20.26 \pm 1.43$ & Ethanol precipitation + protease \\
\hline Ia453su1 21DAP & $19.51 \pm 2.76$ & Ethanol precipitation \\
\hline Ia453su1 40DAP & $20.00 \pm 1.34$ & Ethanol precipitation \\
\hline
\end{tabular}

a Extract concentrations were measured in $1 \times$ PBS. Data are presented as mean \pm standard deviation of three independent replicates. DAP = days after pollination. Means were analyzed for statistically significant differences using one-way ANOVA with Tukey's post-hoc.

\subsection{Hydrodynamic Diameter of Phytoglycogen Extracts from Different Sources}

All phytoglycogen variants had intensity-weighted mean hydrodynamic diameter (i.e., "Z-averages") ranging from $\sim 66-78 \mathrm{~nm}$ with low polydispersity indices (Table 2). In general, these data demonstrated that phytoglycogen hydrodynamic diameter does not depend on plant variety, su1 allele, or harvest time. 
Table 2. Hydrodynamic diameter and polydispersity of phytoglycogen extracts isolated using ethanol precipitation.

\begin{tabular}{lccc}
\hline & & Diameter/nm & PDI \\
\hline A & A619su1-SW & $77.5 \pm 0.63$ & 0.089 \\
\hline B & A632su1-SW & $74.8 \pm 0.096$ & 0.103 \\
\hline C & A632su1-NE & $75.2 \pm 0.371$ & 0.124 \\
\hline D & A632su1-NC & $66.5 \pm 0.643$ & 0.075 \\
\hline E & A632su1-Pu & $70.8 \pm 0.842$ & 0.096 \\
\hline F & A632su1-CM & $76.8 \pm 0.36$ & 0.111 \\
\hline G & Wesu7-A & $68.1 \pm 1.09$ & 0.135 \\
\hline H & Ia453su1 21DAP & $77 \pm 0.53$ & 0.082 \\
\hline I & Ia453su1 40DAP & $74.7 \pm 1.170$ & 0.123 \\
\hline
\end{tabular}

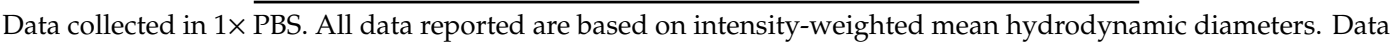
are reported as mean \pm standard deviation of three independent replicates. DAP $=$ days after pollination.

\subsection{Cytotoxicity of Phytoglycogen Extracts from Different Sources}

We characterized the cytotoxicity of phytoglycogen extracts from different sweet corn varieties using different extraction-purification methods by treating NIH3T3 fibroblasts with a range of dilutions of stock extract solutions. First, we compared cells treated with phytoglycogen extracted from 2 different corn lines with the same su1 allele, su1-SW. Both A619su1-SW and A632su1-SW were extracted using the ethanol precipitation protocol. A619su1-SW showed a clear dose-dependent toxicity (Figure 2a), while A632su1-SW showed low toxicity at all concentrations tested (Figure 2b). Likewise, cells exposed to A619su1-SW had a rounded morphology consistent with dead or dying NIH3T3 fibroblasts, whereas cells exposed to A632su1-SW had an elongated morphology consistent with healthy cells and PBS controls (Figure 3). Thus, plants harboring the same su1 mutant can yield phytoglycogen extracts with different cytotoxicity profiles.

(a) A619sul-SW

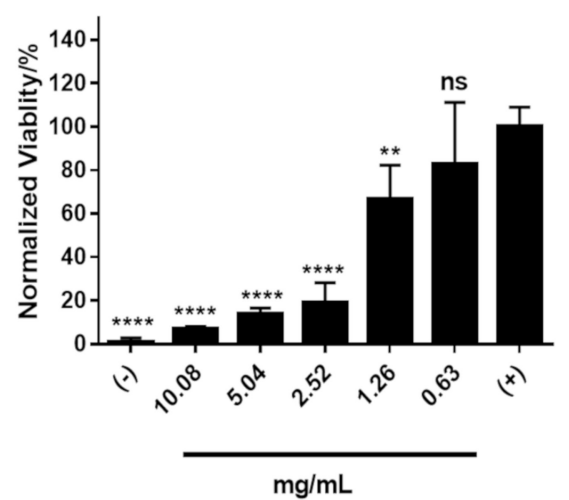

(b) A632sul-SW

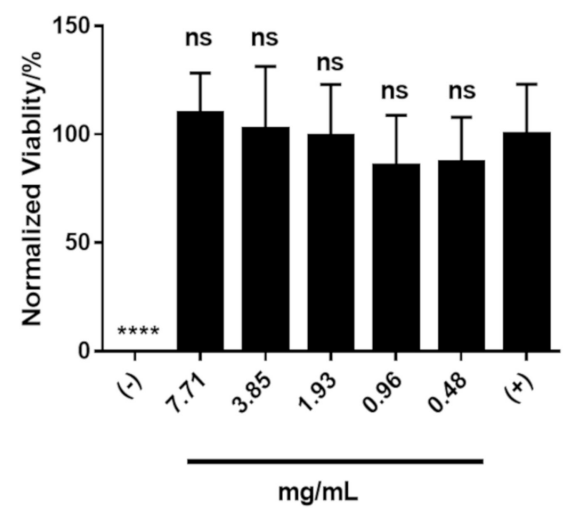

Figure 2. Cytotoxicity of phytoglycogen extracts from two different plant varieties with the su1-SW mutant. Phytoglycogen was extracted from both plant varieties using ethanol precipitation. Cells were treated with $50 v / v \%$ PBS (positive control) or $50 v / v \%$ DMSO (negative control). Data are presented as mean \pm standard deviation $(n=5)$. ${ }^{*}$ indicates statistically significant differences compared to the positive control group; "ns" indicates no difference relative to the positive control group at $\mathrm{t}=24 \mathrm{~h}$. Statistical significance was calculated using a one-way ANOVA followed by Tukey's post-hoc. ${ }^{* *} p<$ 0.01 and $^{* * * *} p<0.0001$. 

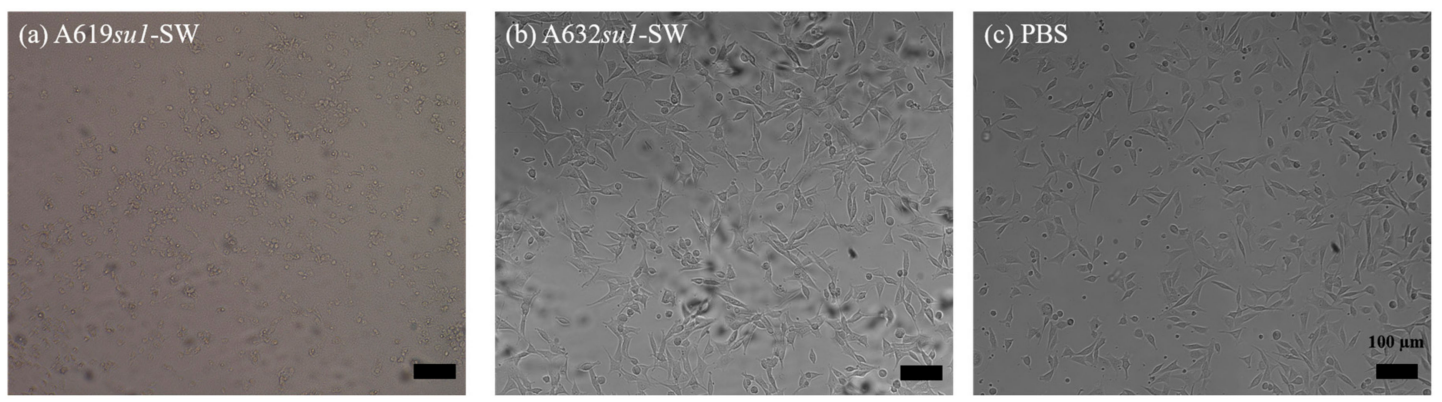

Figure 3. Bright-field micrographs of NIH3T3 cells treated with (a) A619su1-SW, (b) A632su1-SW, or (c) PBS. Scale bar represents $100 \mu \mathrm{m}$ in all images.

Next, we compared the cytotoxicity of phytoglycogen extracts from different su1 mutants in the A632 background. The phytoglycogen extract from A632su1-NE was weakly cytotoxic at concentrations $\geq 4.9 \mathrm{mg} / \mathrm{mL}$ (Figure $4 \mathrm{a}$ ), while that from A632su1-NC was moderately cytotoxic over the same range (Figure $4 \mathrm{~b}$ ). The phytoglycogen extract from A632su1-Pu promoted cell metabolic activity at concentrations $\geq 2.15 \mathrm{mg} / \mathrm{mL}$ (Figure 4c), suggesting that fibroblasts can use this variant as an energy source under the tested conditions $[47,48]$. The phytoglycogen extract from A632su1-CM was moderately cytotoxic at concentrations $\geq 1.1 \mathrm{mg} / \mathrm{mL}$ (Figure $4 \mathrm{~d}$ ). There was no clear relationship between the type of mutation and the cytotoxicity of phytoglycogen produced. In particular, among the single nucleotide polymorphisms, su1-SW was non-toxic, su1-NE was weakly toxic, and su1-NC was moderately toxic. su1-CM, which is characterized by a large insertion and complete loss of ISA1 production, was also moderately toxic. Given that su1-NC results in production of ISA1, albeit a non-functional variant, these observations suggested that cytotoxicity is not correlated with the presence or absence of ISA1 in the plant. Taken together with observations from the A632su1-SW group (Figure $2 \mathrm{~b}$ ), these results demonstrate that plants harboring different su1 mutations can yield phytoglycogen extracts with widely varying cytocompatibility, although cytotoxicity cannot be predicted from the type of mutation alone.

Next, we evaluated the cytotoxicity of phytoglycogen extracts isolated from the Wesu7 variety (su1-NE allele) using different methods. The different extraction methods did not alter the hydrodynamic diameter of phytoglycogen extracts (Table 2 and Table S1). Phytoglycogen extracts isolated using ethanol precipitation induced significant cell death at concentrations $\geq 2.47 \mathrm{mg} / \mathrm{mL}$ (Figure $5 \mathrm{a}$ ), whereas extracts isolated using ethanol precipitation with acid deproteination induced less cell death over the entire concentration range (Figure 5b). In contrast, phytoglycogen extracts isolated using ethanol precipitation and protease treatment strongly stimulated cell metabolic activity at concentrations $\geq 5 \mathrm{mg} / \mathrm{mL}$ (Figure 5c). Collectively, these data further supported the observation that the maize line is an important determinant of phytoglycogen cytotoxicity, given that extracts from the Wesu7 variety with the su1-NE allele that were isolated with ethanol precipitation were more cytotoxic than extracts from the A632 variety with the same allele that were isolated with the same method. These data also suggested that extraction method can alter cytotoxicity, as demonstrated by the weakened cytotoxicity of Wesu7 extracts that were deproteinated after ethanol precipitation. This suggests that a similar extraction protocol could potentially decrease the cytotoxicity of phytoglycogen extracts from A619su1-SW, A632su1-NE, A632su1-NC, or A632su1-CM, which we will explore with future crop harvests. Unexpectedly, protease treatment yielded phytoglycogen extracts from Wesu7 that stimulated cell growth more potently than extracts from A632su1-Pu (Figures 5c and 4c, respectively). It remains to be determined with future crop harvests if protease treatment can generally be applied to switch phytoglycogen extracts from a cytotoxic or cytocompatible state into an energy source. 
(a) A632sul-NE

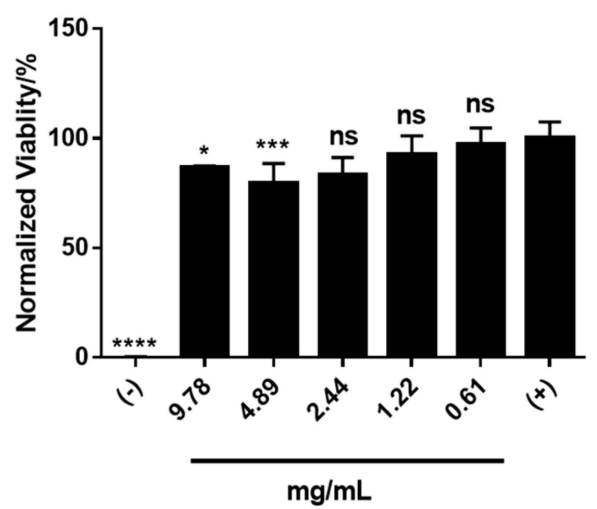

(c) A632sul-Pu

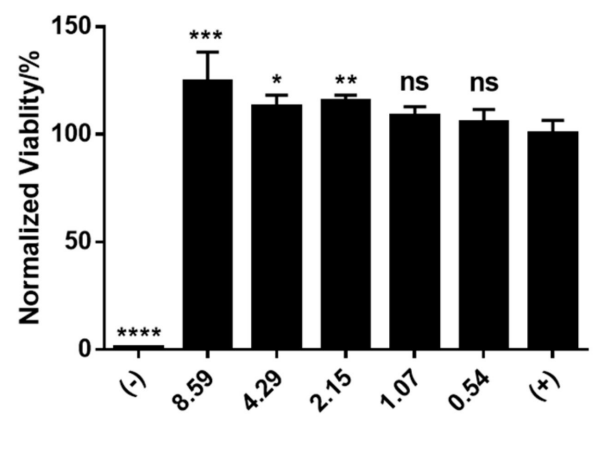

$\mathrm{mg} / \mathrm{mL}$ (b) A632sul-NC

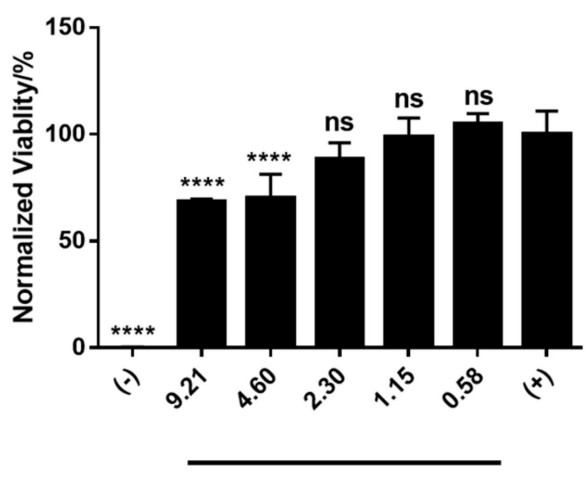

$\mathrm{mg} / \mathrm{mL}$

(d) A632sul-CM

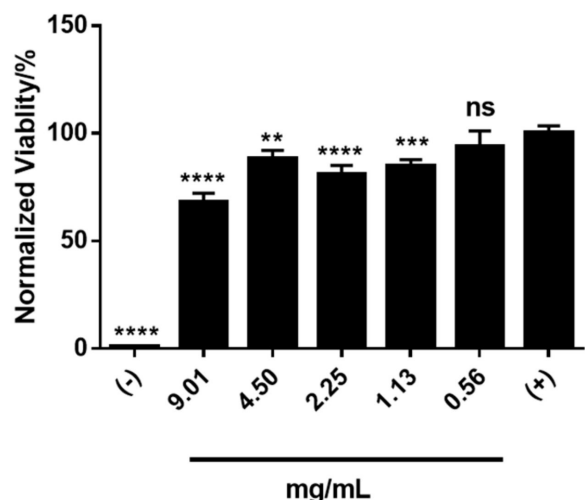

Figure 4. Cytotoxicity of extracts from the same plant with different su1 mutants. Phytoglycogen was extracted from all plants using ethanol precipitation. Cells were treated with $50 v / v \%$ PBS (positive control) or $50 v / v \%$ DMSO (negative control). Data are presented as mean \pm standard deviation $(n=5)$. * indicates statistically significant differences compared to the positive control group; "ns" indicates no difference relative to the positive control group at $\mathrm{t}=24 \mathrm{~h}$. Statistical significance was calculated using a one-way ANOVA followed by Tukey's post-hoc. ${ }^{*} p<0.05,{ }^{* *} p<0.01,{ }^{* * *} p<0.001$ and ${ }^{* * *} p<0.0001$.

(a)

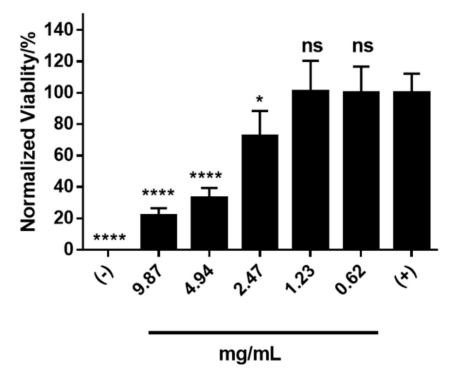

(b)

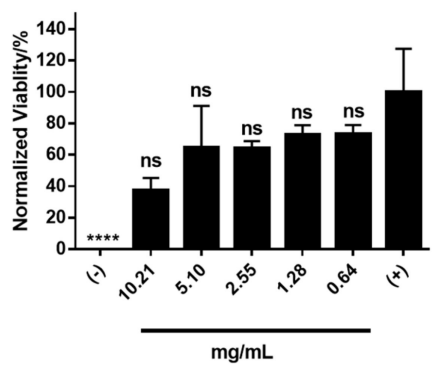

(c)

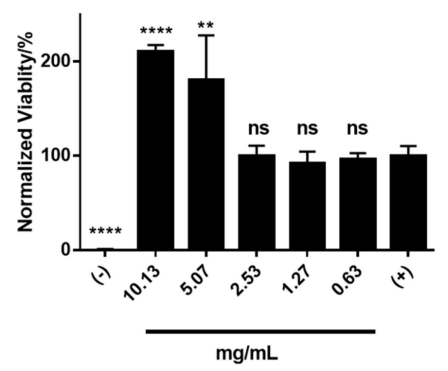

Figure 5. Toxicity of phytoglycogen extracts isolated from Wesu7 using different methods. (a) ethanol precipitation; (b) ethanol precipitation with deproteinization, and (c) ethanol precipitation with protease treatment. Cells were treated with $50 v / v \%$ PBS (positive control) or $50 v / v \%$ DMSO (negative control). Data are presented as mean \pm standard deviation $(n=5) .{ }^{*}$ indicates statistically significant differences compared to the positive control group; "ns" indicates no difference relative to the positive control group at $\mathrm{t}=24 \mathrm{~h}$. Statistical significance was calculated using a one-way ANOVA followed by Tukey's post-hoc. ${ }^{*} p<0.05,{ }^{* *} p<0.01$, and ${ }^{* * *} p<0.0001$. 
Finally, we compared the cytotoxicity of phytoglycogen extracts from Ia453-su1 from which kernels were processed at different times post-pollination. Unexpectedly, kernels processed at maturity (i.e., 40 days after pollination ("DAP")) yielded phytoglycogen extracts that were non-toxic to NIH3T3 fibroblasts at all concentrations tested (Figure $6 \mathrm{~b}$ ), whereas extracts from kernels processed at 21 days after pollination were cytotoxic (Figure 6a). This contrasted with non-toxic phytoglycogen extracts from A632su1-SW and A632su1-Pu, which were extracted 21 days after pollination. It is important to note that the Ia453su1 kernels were from plants grown in different environments (FL and WI), and the difference observed in cytotoxicity of phytoglycogen extracted at 21 DAP and 40 DAP could be due to environmental effects. Thus, these data suggest that pollination time and/or growth location may be determinants of phytoglycogen extract cytotoxicity.

(a) Ia453sul 21DAP

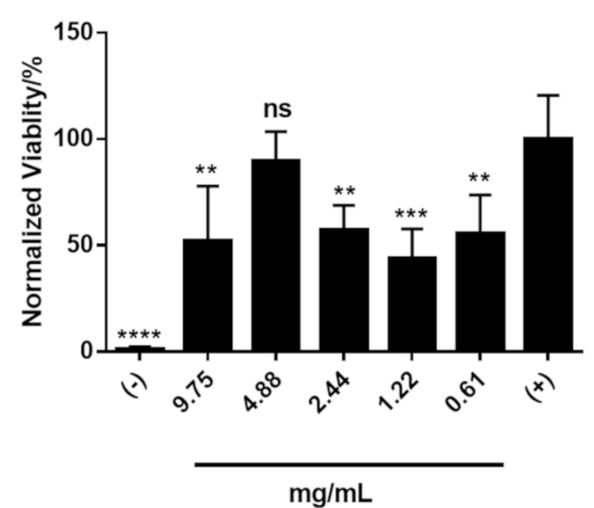

(b) Ia453sul 40DAP

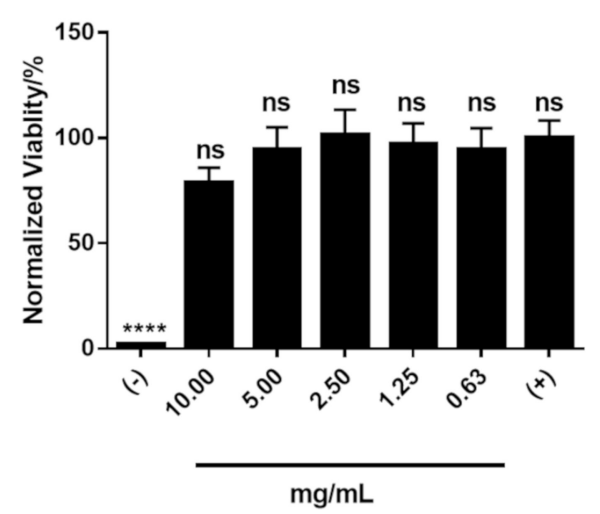

Figure 6. Cytotoxicity of phytoglycogen extracts isolated at different times post-pollination. Phytoglycogen was extracted using ethanol precipitation 21 days after pollination ("Ia435su1 21DAP") or 40 days after pollination ("Ia435su1 40DAP"). Cells were treated with $50 v / v \%$ PBS (positive control) or $50 v / v \%$ DMSO (negative control). Data are presented as mean \pm standard deviation $(n=5)$. * indicates statistically significant differences compared to the positive control group; "ns" indicates no difference relative to the positive control group at $\mathrm{t}=24 \mathrm{~h}$. Statistical significance was calculated using a one-way ANOVA followed by Tukey's post-hoc. ${ }^{* *} p<0.01,{ }^{* * *} p<0.001$ and ${ }^{* * * *} p<0.0001$.

\subsection{Water-Binding Properties of Phytoglycogen Extracts from Different Sources}

The hydration state of polysaccharides, including phytoglycogen, can vary based on their chemical composition [49]. The organization of water molecules around phytoglycogen could aid in understanding and predicting its interactions with biomolecules or cells in physiological conditions [50]. Here, we postulated that the hydration state of phytoglycogen may correlate with cytotoxicity. To measure the water order around phytoglycogen, we collected FTIR spectra of dry and wet extracts, and compared the $R_{\text {network }} / R_{\text {multimer }}$ ratio, which is determined from the integrated signal intensity at different wavenumbers (Figure 7 and Figure S1). A619su1-SW and A632su1-SW had similar $R_{\text {network }} / R_{\text {multimer }}$ ratios, which suggested that their observed differences in cytotoxicity are likely due to features of the plant type (Figure 8a). Among A632 su1 mutants, the $R_{\text {network }} / R_{\text {multimer }}$ ratios varied. We noted that $A 632$ su1 mutants with $R_{\text {network }} / R_{\text {multimer }}$ greater than 1.5 were cytotoxic to fibroblasts at high concentrations, whereas those with $R_{\text {network }} / R_{\text {multimer }}$ less than 1.5 , were non-toxic or stimulated growth (Figure $8 b$ ). All extracts from Wesu7 had similar $R_{\text {network }} / R_{\text {multimer }}$ values, regardless of whether they were extracted with ethanol, ethanol and deproteination, or ethanol and protease treatment (Figure 8c). These observations, taken together with DLS measurements, suggested that the extraction method does not affect the physical properties of phytoglycogen itself, but instead that additional processing steps may remove impurities that are cytotoxic to NIH3T3 cells. In contrast, the $R_{\text {network }} / R_{\text {multimer }}$ of the two Ia453su1 extracts were significantly different from each other, with the cytotoxic extract obtained 21 days after pollination having a smaller ratio than the non-toxic extract obtained $\sim 40$ days post-pollination (Figure $8 \mathrm{~d}$ ). These observations suggest that time post-pollination 
may alter the structure or composition of phytoglycogen in a way that leads to changes in hydration state. Collectively, these observations demonstrate that hydration state is not a reliable predictor of phytoglycogen cytotoxicity in general, although differences in water order between phytoglycogen extracts from A632 or Ia453 variants did correlate with cytotoxicity.

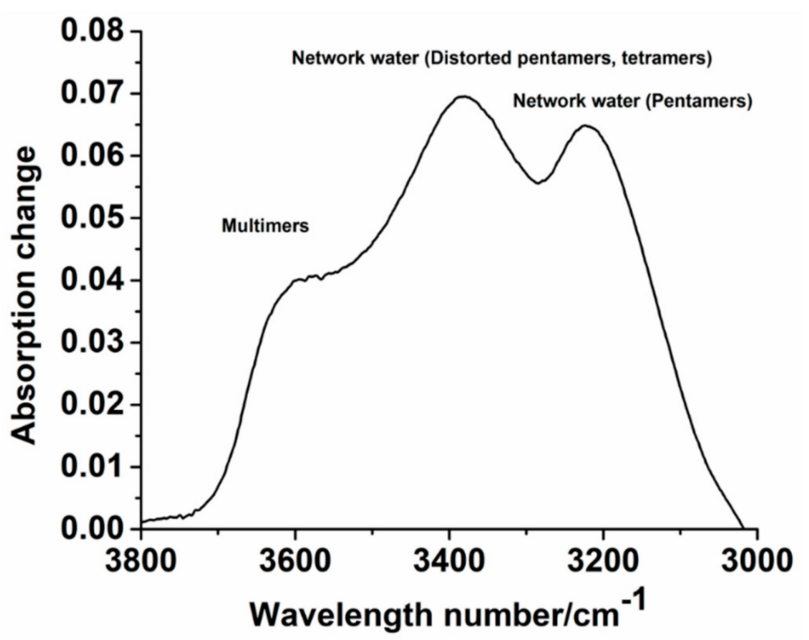

Figure 7. Representative subtracted FTIR spectrum. The peaks located at $\sim 3225,3400$, and $3600 \mathrm{~cm}^{-1}$ are used to determine the $R_{\text {network }} / R_{\text {multimer }}$ Spectra for all phytoglycogen extracts can be found in Supplementary Figure S1.

(a)

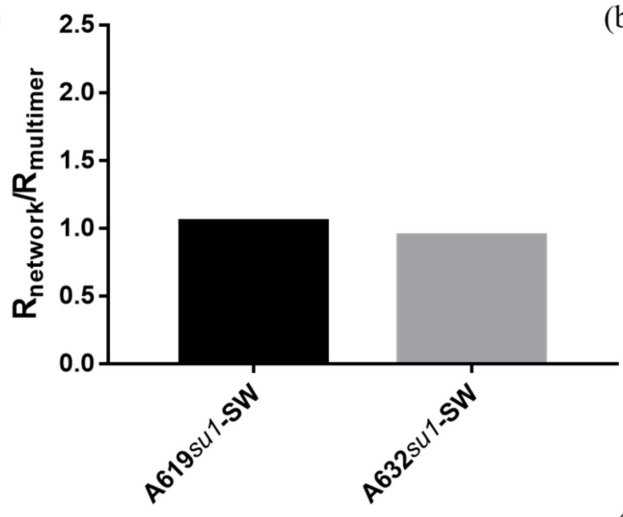

(c)

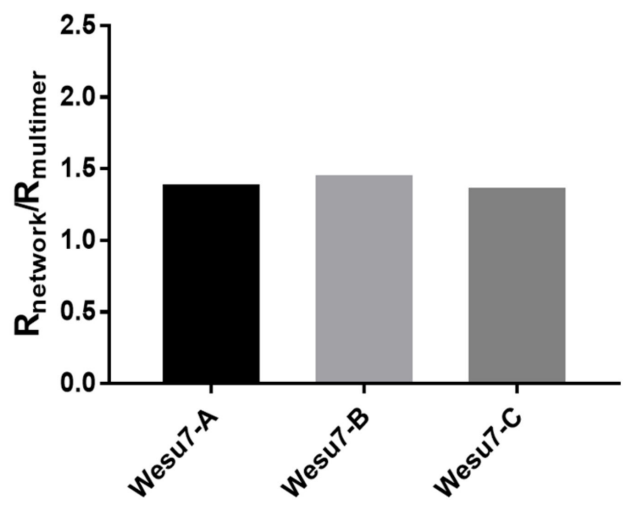

(b)

(d)
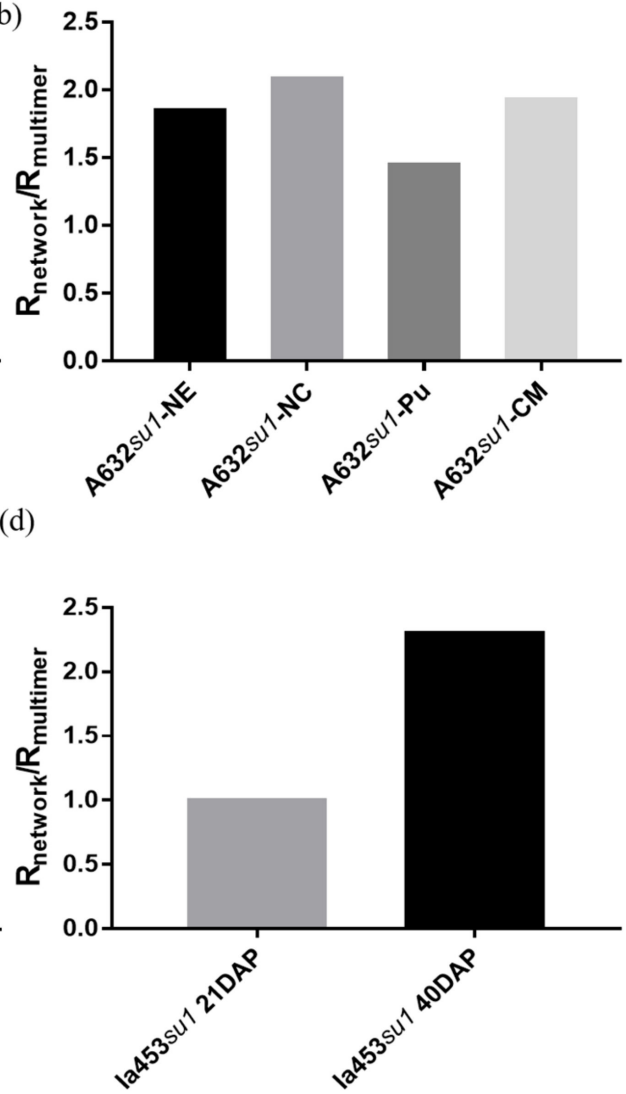

Figure 8. $R_{\text {network }} / R_{\text {multimer }}$ for (a) A619su1-SW and A632su1-SW, (b) A632 with different su1 mutants, (c) Wesu7-A, Wesu7-B, and Wesu7-C, and (d) Ia453su1 harvested 21 days after pollination ("Ia435su1 $21 \mathrm{DAP}$ ") or at 40 days after pollination ("Ia435su1 40DAP"). 


\subsection{Contaminating Protein Impurities in Phytoglycogen Extracts from Different Sources}

In all phytoglycogen samples, a peak was observed in FTIR spectra within the range of $\sim 1700 \mathrm{~cm}^{-1}$ to $1500 \mathrm{~cm}^{-1}$, which is associated with the vibration of amide bonds of proteins [51] (Figures S2 and S3). Because protein quantification based on amide FTIR signal can vary due to sample preparation, we subjected each extract to the BCA assay to quantify the amount of protein contaminants (Figure 9). A632su1-SW and A619su1-SW had a similar percentage of protein impurities (Figure 9a). A632su1-CM had a significantly higher protein content than all other A632 su1 mutants (Figure 9b). Wesu7 extracts treated with protease had lower protein content than extracts obtained with ethanol precipitation alone or those that were deproteinated with acid (Figure 9c). These observations suggested that protease treatment removed protein impurities more effectively than acidic deproteination. Phytoglycogen extracted from Ia453su1 40 days post-pollination had a lower protein contaminant concentration than extracts obtained 21 days post-pollination (Figure 9d). In many instances, protein contaminant concentration correlated with cytotoxicity. In particular, A632su1-CM was the most toxic extract from this plant and also had the highest protein contaminant concentration. Wesu-7C, which was extracted with ethanol and treated with protease, had the lowest protein contaminant concentration and promoted cell growth when compared to other Wesu-7 extracts. Ia453su1 extracts obtained 40 days post-pollination had a lower protein contaminant concentration and lower cytotoxicity than extracts obtained after 21 days. Collectively, these observations suggest that protein impurities may contribute to the cytotoxicity profile of phytoglycogen extracts.

(a)

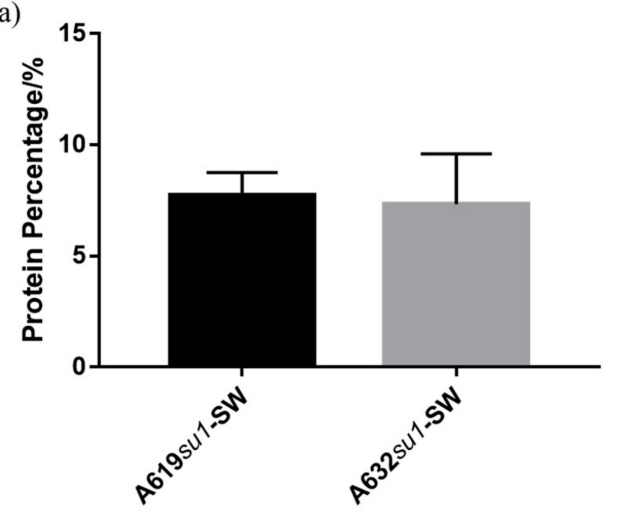

(c)

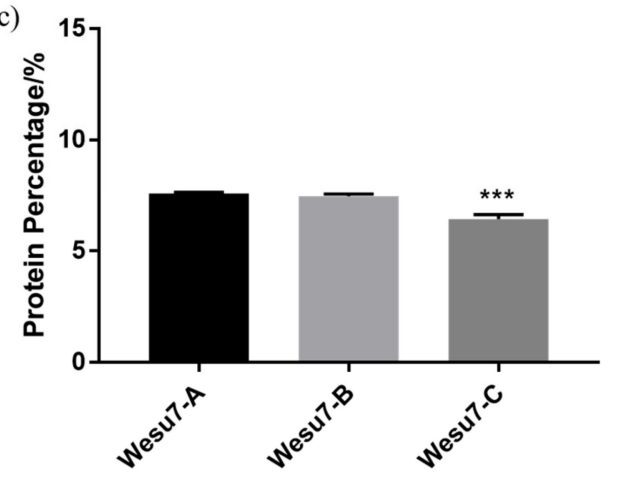

(b)

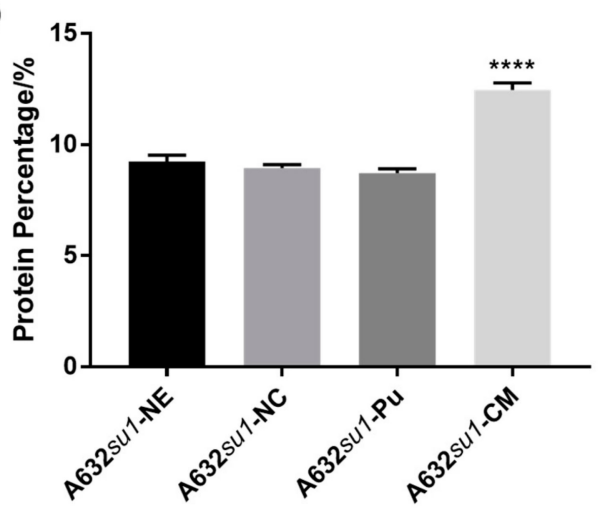

(d)

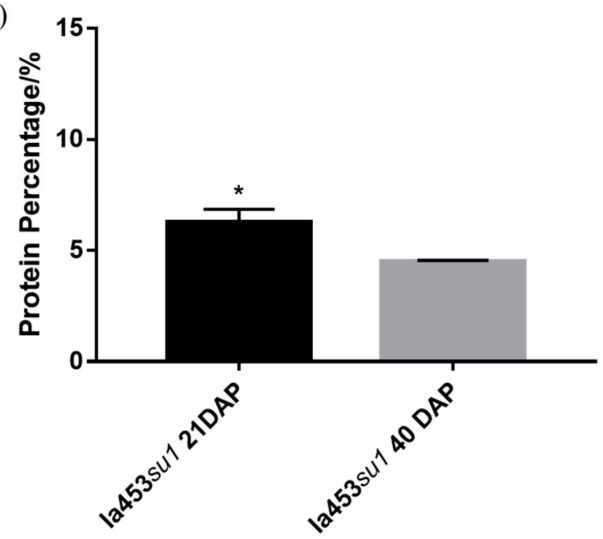

Figure 9. Protein content of phytoglycogen extracts determined using the BCA assay. (a) A619su1-SW and A632su1-SW, (b) A632 with different su1 mutants, (c) Wesu7-A, Wesu7-B, and Wesu7-C, and (d) Ia453su1 extracted at 21 days or 40 days post-pollination. Data are presented as mean \pm standard deviation $(n=3)$. Statistically significant differences between the means were calculated using an unpaired Student's $\mathbf{t}$ test for (a) and (d). For (b) and (c) data were analyzed with one-way ANOVA followed by Tukey's post-hoc. ${ }^{*} p<0.05,{ }^{* * *} p<0.001$ and ${ }^{* * *} p<0.0001$. 


\section{Materials and Methods}

\subsection{Phytoglycogen Extract Sources}

In this experiment, we characterized five naturally-occurring sugary-1 alleles introgressed into one field corn line (A632) plus another 2 lines containing the su1-NE mutation (Wesu7 and Ia453) and one line (A619) containing the su1-SW allele. The sweet corn kernels utilized in this study were grown in Wisconsin and harvested for another experiment previously described [52]. Kernels were harvested and frozen 21 days after pollination, with exception of sample "Ia453su1 40 DAP", which was grown in Florida in the fall of 2017 and harvested at maturity, 40 days after pollination.

\subsection{Phytoglycogen Extraction and Purification}

A: Ethanol $(\mathrm{EtOH})$ precipitation method: Phytoglycogen extractions were performed as reported before [32]. Briefly, a volume of water equivalent to six times the weight of each sample of either lyophilized powdered kernels or fresh frozen kernels was added. Frozen kernels were pulverized using a mortar and pestle, while powdered kernels were vortexed for 30 seconds. The suspensions were then passed through a $50 \mu \mathrm{m}$ filter. Three volumes of $100 \%$ EtOH was added to each sample and centrifuged at $8000 \times g$ for $20 \mathrm{~min}$. The supernatant was decanted and the pellet re-dissolved in $30 \mathrm{~mL}$ of $100 \% \mathrm{EtOH}$ and centrifuged at $8000 \times g$ for $10 \mathrm{mins}$. This wash was repeated 2 times. The pellet was then dried under vacuum and maintained in a $60^{\circ} \mathrm{C}$ oven for $30 \mathrm{~min}$ until powders were completely dry.

B: Ethanol precipitation with deproteinization: Phytoglycogen extractions were performed as described before [38]. Briefly, $10 \mathrm{~g}$ of kernels were ground in $60 \mathrm{~mL}$ of cold $\mathrm{H}_{2} \mathrm{O}$ with a mortar and pestle. The homogenates were collected and passed through a $50 \mu \mathrm{m}$ disposable filter. The solid was further extracted twice using deionized water. The combined liquid was adjusted to $\mathrm{pH} 4.9$ with acetic acid and placed at $4{ }^{\circ} \mathrm{C}$ for $2 \mathrm{~h}$ to induce protein precipitation. The liquid was then centrifuged at $10,000 \times g$ at $4^{\circ} \mathrm{C}$ and the creamy layer and precipitate were removed. The supernatant was adjusted to pH 7.0 and autoclaved at $121^{\circ} \mathrm{C}$ for $60 \mathrm{~min}$. The supernatant was collected and 3 volumes of ethanol were added to precipitate polysaccharides. The precipitate was washed with three cycles of ethanol. After removing the bulk of ethanol by filtration, the solid material was dried in an oven at $37^{\circ} \mathrm{C}$ to remove residual ethanol and powdered in a mortar and pestle.

C: Ethanol precipitation and protease treatment: Phytoglycogen extractions were performed as reported before [46]. Five grams of kernels were ground in $25 \mathrm{~mL}$ of $250 \mathrm{mM}$ Tricine buffer, $\mathrm{pH} 7.5$, with protease (2.5 units/mL; bacterial type XIV, Sigma-Aldrich, Castle Hill, NSW, Australia) at $37^{\circ} \mathrm{C}$ for $30 \mathrm{~min}$. To this solution, $25 \mathrm{~mL}$ cold Tricine buffer was added followed by centrifugation at $4000 \times g$ for $10 \mathrm{~min}$. The supernatant was collected and 4 volumes of absolute EtOH added. The suspension was then centrifuged for 10 mins at $4000 \times g$. The pellet was then re-dissolved in $15 \mathrm{~mL}$ DMSO containing $0.05 \%(w / w)$ lithium bromide and incubated at $80{ }^{\circ} \mathrm{C}$ in a water bath overnight. The supernatant was collected and 4 volumes of EtOH added, followed by centrifugation. Residual EtOH was removed by filtration and dried in an oven at $37^{\circ} \mathrm{C}$ for 30 mins.

The protein content of each phytoglycogen extract was determined using the BCA assay (ThermoFisher Scientific) by adapting procedures reported previously [49].

\subsection{Dynamic Light Scattering}

For DLS measurements, all phytoglycogen extracts reported in Table 2 were purified using ethanol precipitation. All phytoglycogen extracts were dissolved in $1 \mathrm{~mL}$ of distilled water at a weight to volume ratio of $10 \mathrm{mg} / \mathrm{mL}$. Samples were then sonicated for $30 \mathrm{~min}$ in a water bath sonicator. Particulate matter was removed by centrifugation. Samples were then diluted 5 times in 1.25× PBS followed by filtration through a $0.2 \mu \mathrm{m}$ filter. $1 \mathrm{~mL}$ of each sample was then run on a Malvern Zetasizer Ultra (Malvern Instruments Ltd., UK). A refractive index of 1.33457 was used based on dextrin. Each sample 
was run 3 times and the mean and standard deviation are reported. The polydispersity index is also reported.

\subsection{Cell Toxicity Using Fibroblasts}

For in vitro cytotoxicity experiments, phytoglycogen extracts were dissolved in PBS at $20 \mathrm{mg} / \mathrm{mL}$ and vortexed vigorously for $5 \mathrm{~min}$ before placing in a sonicating water bath for $30 \mathrm{~min}$. The final solution was sterilized by passing it through a $0.22 \mu \mathrm{m}$ EMD Millipore $^{\mathrm{TM}}$ Millex $^{\mathrm{TM}}$ (Millipore Sigma, Burlington, MA, USA) sterile syringe filter. The final phytoglycogen solutions were obtained as milky transparent stocks and were diluted as reported.

The toxicity of different phytoglycogen extracts was evaluated by measuring the metabolic activity of NIH3T3 fibroblasts in vitro using the CellTiter-Blueßreagent (PR-G8080, Promega, Madison, WI, USA), similar to methods reported previously $[53,54]$. Cells were maintained at $37^{\circ} \mathrm{C}$ and $5 \% \mathrm{CO}_{2}$ in Dulbecco's Modified Eagle Medium (DMEM) supplemented with 10\% (v/v) fetal bovine serum (Biochrom, Berlin, Germany), 1\% penicillin-streptomycin, and 1\% $(v / v)$ L-glutamine, referred to as "complete fibroblast media". Before cell seeding, cells were harvested using trypsin-EDTA $(0.25 \%$ trypsin) and counted with a hemocytometer (Fisher Scientific, Hampton, NH, USA). Then cells were aliquoted into a clear tissue culture-treated 96-well microplate (20,000 cells per well) in $50 \mu \mathrm{L}$ of complete fibroblast media. For experimental groups, cells were treated with $50 \mu \mathrm{L}$ of sterile filtered solutions of phytoglycogen extracts in PBS at various dilutions prepared from each stock. For negative and positive controls, cells were treated with $50 \mu \mathrm{L}$ PBS or DMSO, respectively. Cells were incubated at $37^{\circ} \mathrm{C}$ for $24 \mathrm{~h}$, at which point the culture media was aspirated and replaced with $100 \mu \mathrm{L}$ fresh complete fibroblast media. $20 \mu \mathrm{L}$ of CellTiter-Blueßreagent (PR-G8080, Promega) was then added to each well. Fluorescence emission of each well was measured using a SpectraMax M3 plate reader (excitation = $560 \mathrm{~nm}$, emission $=590 \mathrm{~nm}$ ) at 1, 2, 3, and $4 \mathrm{~h}$.

\subsection{FTIR Spectroscopy}

The interaction between different phytoglycogen extracts and water was investigated using FTIR spectroscopy by adapting methods reported previously [49]. In brief, $1 \mathrm{mg}$ of phytoglycogen extract (dry powder) was deposited onto a ZnSe-diamond ATR crystal. Spectra were collected on a Bruker Vertex 70 FTIR spectrometer equipped with an MCT-A detector using an incident angle of $45^{\circ}$. Spectra were acquired at a resolution of $4 \mathrm{~cm}^{-1}$. Spectra were collected both before and after adding $0.1 \mu \mathrm{L}$ ultra-pure water to dry phytoglycogen extract samples. Water organization around phytoglycogen extracts was calculated by quantifying spectral changes, according to methods reported previously [49]. In short, each water band was calculated by integrating a $40 \mathrm{~cm}^{-1}$ window from the component centers (e.g. 3225,3400 , and $3600 \mathrm{~cm}^{-1}$ ) with Fourier self-deconvolution. The integrated area is proportional to the number of absorbing water molecules in the spectral range, where $\mathrm{A}_{3600}$ corresponds to multimer, $\mathrm{A}_{3400}$ corresponds to distorted pentamers or tetramers, and $\mathrm{A}_{3225}$ corresponds to pentamers [55]. Using these absorbance values, the spectral parameters $R_{\text {network }}\left(R_{\text {network }}=A_{3225} / A_{3400}\right)$ and $R_{\text {multimer }}$ $\left(R_{\text {multimer }}=A_{3600} / A_{3225}\right)$ were calculated for each phytoglycogen extract. These parameters provide information about the relative populations of the different water types and are known to be sensitive to the structural arrangement of hydrogen bonds [55-61].

\subsection{Statistical Analysis}

All cell experiments were conducted with five technical replicates. Data are reported as mean and standard deviation. Statistically significance differences between data points were determined using a one-way ANOVA followed by Tukey's post-hoc or Student's t-tests in GraphPad Prism software (GraphPad Software, San Diego, CA, USA). 


\section{Conclusions}

This study reports the characterization of the cytocompatibility of phytoglycogen extracts from different maize sources. Phytoglycogen extracted from A632su1-SW was not cytotoxic, whereas phytoglycogen from A619su1-SW was. Among extracts from A632 varieties with different su1 mutants, A632su1-NE, -NC, and-CM were cytotoxic, whereas A632su1-Pu promoted cell growth. Changing the extraction methods improved the cytocompatibility of phytoglycogen extracts from Wesu7, whereas changing the harvest time improved the cytocompatibility of extracts from Ia435su1. Hydrodynamic diameter and solubility did not correlate with cytotoxicity in any case. Within A632, Wesu7, and Ia435 plant varieties, the concentration of protein contaminants correlated with cytotoxicity. Among A632 and Ia435 varieties, water-binding properties also correlated with cytotoxicity. Although the mechanism by which phytoglycogen extracts induce cell death remains unknown, collectively these data demonstrate that phytoglycogen extracts are not uniformly cytocompatible. Rather, these data demonstrate that the maize variant, plant genotype, protein contaminants, and water-binding properties are determinants of the cytocompatibility of phytoglycogen extracts. Thus, future efforts that employ maize phytoglycogen extracts for medical or biotechnology applications should consider the source and processing methods when evaluating safety and toxicity.

Supplementary Materials: The following are available online. Figure S1: FTIR spectra of water binding to phytoglycogen, Figure S2: FTIR spectra of dry phytoglycogen extracts, Figure S3: FTIR spectra of phytoglycogen protein contaminants, Table S1: hydrodynamic diameters of Wesu7 extracts (su1-NE) with different processing steps.

Author Contributions: R.L., S.K.B., M.F.R.R.J., and G.A.H. designed the experiments, analyzed the data, and wrote the paper. W.F.T. and M.F.F.R.J. provided maize kernels. All authors have read and agreed to the published version of the manuscript.

Funding: This work was funded by the National Institutes of Health (R35 GM133697), National Science Foundation (DMR-1455201), and the National Institute of Food and Agriculture (2018-51181-28419). The content is solely the responsibility of the authors and does not necessarily represent the official views of the National Science Foundation, National Institutes of Health or National Institute of Food and Agriculture.

Conflicts of Interest: The authors have no conflicts of interest to declare.

\section{References}

1. Basu, A.; Kunduru, K.R.; Abtew, E.; Domb, A.J. Polysaccharide-based conjugates for biomedical applications. Bioconjugate Chem. 2015, 26, 1396-1412. [CrossRef] [PubMed]

2. Mizrahy, S.; Peer, D. Polysaccharides as building blocks for nanotherapeutics. Chem. Soc. Rev. 2012, 41, 2623-2640. [CrossRef] [PubMed]

3. Sutherland, I.W. Biosynthesis and composition of gram-negative bacterial extracellular and wall polysaccharides. Annu. Rev. Microbiol. 1985, 39, 243-270. [CrossRef] [PubMed]

4. Luo, A.; He, X.; Zhou, S.; Fan, Y.; Luo, A.; Chun, Z. Purification, composition analysis and antioxidant activity of the polysaccharides from Dendrobium nobile Lindl. Carbohydr. Polym. 2010, 79, 1014-1019. [CrossRef]

5. Xu, S.-Y.; Huang, X.; Cheong, K.-L. Recent advances in marine algae polysaccharides: Isolation, structure, and activities. Mar. Drugs 2017, 15, 388. [CrossRef] [PubMed]

6. Ferreira, S.S.; Passos, C.P.; Madureira, P.; Vilanova, M.; Coimbra, M.A. Structure-function relationships of immunostimulatory polysaccharides: A review. Carbohydr. Polym. 2015, 132, 378-396. [CrossRef] [PubMed]

7. Romdhane, M.B.; Haddar, A.; Ghazala, I.; Jeddou, K.B.; Helbert, C.B.; Ellouz-Chaabouni, S. Optimization of polysaccharides extraction from watermelon rinds: Structure, functional and biological activities. Food Chem. 2017, 216, 355-364. [CrossRef]

8. Han, S.-B.; Lee, C.W.; Kang, J.S.; Yoon, Y.D.; Lee, K.H.; Lee, K.; Park, S.-K.; Kim, H.M. Acidic polysaccharide from Phellinus linteus inhibits melanoma cell metastasis by blocking cell adhesion and invasion. Int. Immunopharmacol. 2006, 6, 697-702. [CrossRef]

9. Morra, M.; Cassineli, C. Non-fouling properties of polysaccharide-coated surfaces. J. Biomater. Sci. Polym. Ed. 1999, 10, 1107-1124. [CrossRef] 
10. Richert, L.; Lavalle, P.; Payan, E.; Shu, X.Z.; Prestwich, G.D.; Stoltz, J.-F.; Schaaf, P.; Voegel, J.-C.; Picart, C. Layer by layer buildup of polysaccharide films: Physical chemistry and cellular adhesion aspects. Langmuir 2004, 20, 448-458. [CrossRef]

11. Cheng, Y.; Tsao, C.Y.; Wu, H.C.; Luo, X.; Terrell, J.L.; Betz, J.; Payne, G.F.; Bentley, W.E.; Rubloff, G.W. Electroaddressing functionalized polysaccharides as model biofilms for interrogating cell signaling. Adv. Funct. Mater. 2012, 22, 519-528. [CrossRef]

12. Snapper, C.M.; Mond, J.J. A model for induction of T cell-independent humoral immunity in response to polysaccharide antigens. J. Immunol. 1996, 157, 2229-2233. [PubMed]

13. Kodama, N.; Komuta, K.; Sakai, N.; Nanba, H. Effects of D-Fraction, a polysaccharide from Grifola frondosa on tumor growth involve activation of NK cells. Biol. Pharm. Bull 2002, 25, 1647-1650. [CrossRef] [PubMed]

14. Shao, B.-M.; Dai, H.; Xu, W.; Lin, Z.-B.; Gao, X.-M. Immune receptors for polysaccharides from Ganoderma lucidum. Biochem. Biophys. Res. Commun. 2004, 323, 133-141. [CrossRef]

15. Okuyama, K.; Noguchi, K.; Kanenari, M.; Egawa, T.; Osawa, K.; Ogawa, K. Structural diversity of chitosan and its complexes. Carbohydr. Polym. 2000, 41, 237-247. [CrossRef]

16. Jiao, G.; Yu, G.; Zhang, J.; Ewart, H. Chemical structures and bioactivities of sulfated polysaccharides from marine algae. Mar. Drugs 2011, 9, 196-223. [CrossRef]

17. Chandrasekaran, R.; Radha, A. Molecular architectures and functional properties of gellan gum and related polysaccharides. Trends Food Sci. Technol. 1995, 6, 143-148. [CrossRef]

18. López-Pérez, P.M.; da Silva, R.M.; Serra, C.; Pashkuleva, I.; Reis, R.L. Surface phosphorylation of chitosan significantly improves osteoblast cell viability, attachment and proliferation. J. Mater. Chem. 2010, 20, 483-491. [CrossRef]

19. Silva, S.S.; Luna, S.M.; Gomes, M.E.; Benesch, J.; Pashkuleva, I.; Mano, J.F.; Reis, R.L. Plasma surface modification of chitosan membranes: Characterization and preliminary cell response studies. Macromol. Biosci. 2008, 8, 568-576. [CrossRef]

20. Felt, O.; Buri, P.; Gurny, R. Chitosan: A unique polysaccharide for drug delivery. Drug Dev. Ind. Pharm. 1998, 24, 979-993. [CrossRef]

21. Janes, K.; Calvo, P.; Alonso, M. Polysaccharide colloidal particles as delivery systems for macromolecules. Adv. Drug Deliv. Rev. 2001, 47, 83-97. [CrossRef]

22. Suh, J.-K.F.; Matthew, H.W. Application of chitosan-based polysaccharide biomaterials in cartilage tissue engineering: A review. Biomaterials 2000, 21, 2589-2598.

23. Lee, K.Y.; Jeong, L.; Kang, Y.O.; Lee, S.J.; Park, W.H. Electrospinning of polysaccharides for regenerative medicine. Adv. Drug Deliv. Rev. 2009, 61, 1020-1032. [CrossRef]

24. Shapiro, E.D.; Berg, A.T.; Austrian, R.; Schroeder, D.; Parcells, V.; Margolis, A.; Adair, R.K.; Clemens, J.D. The protective efficacy of polyvalent pneumococcal polysaccharide vaccine. N. Engl. J. Med. 1991, 325, 1453-1460. [CrossRef]

25. Smit, P.; Oberholzer, D.; Hayden-Smith, S.; Koornhof, H.J.; Hilleman, M.R. Protective efficacy of pneumococcal polysaccharide vaccines. JAMA 1977, 238, 2613-2616. [CrossRef]

26. Morris, G.A.; Kök, S.M.; Harding, S.E.; Adams, G.G. Polysaccharide drug delivery systems based on pectin and chitosan. Biotechnol. Genet. Eng. Rev. 2010, 27, 257-284. [CrossRef]

27. García-González, C.; Alnaief, M.; Smirnova, I. Polysaccharide-based aerogels-Promising biodegradable carriers for drug delivery systems. Carbohydr. Polym. 2011, 86, 1425-1438. [CrossRef]

28. Nickels, J.D.; Atkinson, J.; Papp-Szabo, E.; Stanley, C.; Diallo, S.O.; Perticaroli, S.; Baylis, B.; Mahon, P.; Ehlers, G.; Katsaras, J. Structure and hydration of highly-branched, monodisperse phytoglycogen nanoparticles. Biomacromolecules 2016, 17, 735-743. [CrossRef]

29. Scheffler, S.L.; Wang, X.; Huang, L.; San-Martin Gonzalez, F.; Yao, Y. Phytoglycogen octenyl succinate, an amphiphilic carbohydrate nanoparticle, and $\varepsilon$-polylysine to improve lipid oxidative stability of emulsions. $J$. Agric. Food Chem. 2009, 58, 660-667. [CrossRef]

30. Anderson, B.A.; Singh, R.P.; Rovedo, C. Use of phytoglycogen extracted from corn to increase the bowl-life of breakfast cereal. J. Food Process Eng. 2003, 26, 315-322. [CrossRef]

31. Singh, R.P.; Rovedo, C.O.; Cura, J.A. Phytoglycogen coated food and process of preparing. Google Patents 2002. 
32. Lu, F.; Mencia, A.; Bi, L.; Taylor, A.; Yao, Y.; HogenEsch, H. Dendrimer-like alpha-d-glucan nanoparticles activate dendritic cells and are effective vaccine adjuvants. J. Control. Release 2015, 204, 51-59. [CrossRef] [PubMed]

33. Lu, F.; Mosley, Y.-Y.C.; Rosales, R.J.R.; Carmichael, B.E.; Elesela, S.; Yao, Y.; HogenEsch, H. Alpha-D-glucan nanoparticulate adjuvant induces a transient inflammatory response at the injection site and targets antigen to migratory dendritic cells. npj Vaccines 2017, 2, 4. [CrossRef] [PubMed]

34. Shamana, H.; Grossutti, M.; Papp-Szabo, E.; Miki, C.; Dutcher, J.R. Unusual polysaccharide rheology of aqueous dispersions of soft phytoglycogen nanoparticles. Soft Matter 2018, 14, 6496-6505. [CrossRef]

35. Zeeman, S.C.; Umemoto, T.; Lue, W.-L.; Au-Yeung, P.; Martin, C.; Smith, A.M.; Chen, J. A mutant of Arabidopsis lacking a chloroplastic isoamylase accumulates both starch and phytoglycogen. Plant Cell 1998, 10, 1699-1711. [CrossRef]

36. Wong, K.-S.; Kubo, A.; Jane, J.-l.; Harada, K.; Satoh, H.; Nakamura, Y. Structures and properties of amylopectin and phytoglycogen in the endosperm of sugary-1 mutants of rice. J. Cereal Sci. 2003, 37, 139-149. [CrossRef]

37. Putaux, J.-L.; Buléon, A.; Borsali, R.; Chanzy, H. Ultrastructural aspects of phytoglycogen from cryo-transmission electron microscopy and quasi-elastic light scattering data. Int. J. Biol. Macromol. 1999, 26, 145-150. [CrossRef]

38. Huang, L.; Yao, Y. Particulate structure of phytoglycogen nanoparticles probed using amyloglucosidase. Carbohydr. Polym. 2011, 83, 1665-1671. [CrossRef]

39. Tateishi, K.; Nakano, A. Effects of degree of branching on dispersion stability of phytoglycogen in aqueous solution. Biosci. Biotechnol. Biochem. 1997, 61, 455-458. [CrossRef]

40. Wattebled, F.; Dong, Y.; Dumez, S.; Delvallé, D.; Planchot, V.; Berbezy, P.; Vyas, D.; Colonna, P.; Chatterjee, M.; Ball, S. Mutants of Arabidopsis lacking a chloroplastic isoamylase accumulate phytoglycogen and an abnormal form of amylopectin. Plant Physiol. 2005, 138, 184-195. [CrossRef]

41. Black, R.; Loerch, J.; McArdle, F.; Creech, R. Genetic interactions affecting maize phytoglycogen and the phytoglycogen-forming branching enzyme. Genetics 1966, 53, 661.

42. Nakamura, Y.; Umemoto, T.; Takahata, Y.; Komae, K.; Amano, E.; Satoh, H. Changes in structure of starch and enzyme activities affected by sugary mutations in developing rice endosperm. Possible role of starch debranching enzyme (R-enzyme) in amylopectin biosynthesis. Physiol. Plant. 1996, 97, 491-498. [CrossRef]

43. Doehlert, D.C.; Knutson, C.A. Two classes of starch debranching enzymes from developing maize kernels. J. Plant Physiol. 1991, 138, 566-572. [CrossRef]

44. Tracy, W.F.; Whitt, S.R.; Buckler, E.S. Recurrent mutation and genome evolution: Example of Sugary1 and the origin of sweet maize. Crop Sci. 2006, 46 (Suppl. 1), S-49-S-54. [CrossRef]

45. Trimble, L.; Shuler, S.; Tracy, W.F. Characterization of five naturally occurring alleles at the sugary1 locus for seed composition, seedling emergence, and isoamylase1 activity. Crop Sci. 2016, 56, 1927-1939. [CrossRef]

46. Powell, P.O.; Sullivan, M.A.; Sweedman, M.C.; Stapleton, D.I.; Hasjim, J.; Gilbert, R.G. Extraction, isolation and characterisation of phytoglycogen from su-1 maize leaves and grain. Carbohydr. Polym. 2014, 101, 423-431. [CrossRef]

47. Stetten, D., Jr.; Stetten, M.R. Glycogen metabolism. Physiol. Rev. 1960, 40, 505-537. [CrossRef]

48. Bergström, J.; Hultman, E. A study of the glycogen metabolism during exercise in man. Scand. J. Clin. Lab. Invest. 1967, 19, 218-228. [CrossRef]

49. Grossutti, M.; Dutcher, J.R. Correlation between chain architecture and hydration water structure in polysaccharides. Biomacromolecules 2016, 17, 1198-1204. [CrossRef]

50. Ball, P. Water as an active constituent in cell biology. Chem. Rev. 2008, 108, 74-108. [CrossRef]

51. Guerrero, P.; Kerry, J.P.; de la Caba, K. FTIR characterization of protein-polysaccharide interactions in extruded blends. Carbohydr. Polym. 2014, 111, 598-605. [CrossRef]

52. Shuler, S.L.; Boehlein, S.K.; Hannah, L.; Tracy, W.F. Endosperm Carbohydrates and Debranching Enzyme Activity in Five Native sugary1 Alleles in Maize. Crop Sci. 2017, 57, 3068-3074. [CrossRef]

53. Restuccia, A.; Fettis, M.M.; Farhadi, S.A.; Molinaro, M.D.; Kane, B.; Hudalla, G.A. Evaluation of Self-Assembled Glycopeptide Nanofibers Modified with N, N'-Diacetyllactosamine for Selective Galectin-3 Recognition and Inhibition. ACS Biomater. Sci. Eng. 2018, 4, 3451-3459. [CrossRef]

54. Restuccia, A.; Tian, Y.F.; Collier, J.H.; Hudalla, G.A. Self-assembled glycopeptide nanofibers as modulators of galectin-1 bioactivity. Cell. Mol. Bioeng. 2015, 8, 471-487. [CrossRef] 
55. Binder, E.; Tan, L.; Chin, L.; Handl, J.; Richard, J. Worldwide occurrence of mycotoxins in commodities, feeds and feed ingredients. Anim. Feed Sci. Technol. 2007, 137, 265-282. [CrossRef]

56. Liu, D.; Ma, G.; Levering, L.M.; Allen, H.C. Vibrational spectroscopy of aqueous sodium halide solutions and air- liquid interfaces: Observation of increased interfacial depth. J. Phys. Chem. B 2004, 108, 2252-2260. [CrossRef]

57. Walrafen, G.; Chu, Y. Linearity between structural correlation length and correlated-proton Raman intensity from amorphous ice and supercooled water up to dense supercritical steam. J. Phys. Chem. A 1995, 99, 11225-11229. [CrossRef]

58. Leikin, S.; Parsegian, V.; Yang, W.-H.; Walrafen, G. Raman spectral evidence for hydration forces between collagen triple helices. Proc. Natl. Acad. Sci. USA 1997, 94, 11312-11317. [CrossRef]

59. Ide, M.; Mori, T.; Ichikawa, K.; Kitano, H.; Tanaka, M.; Mochizuki, A.; Oshiyama, H.; Mizuno, W. Structure of water sorbed into poly (MEA-co-HEMA) films as examined by ATR- IR spectroscopy. Langmuir 2003, 19, 429-435. [CrossRef]

60. Uchida, T.; Osawa, M.; Lipkowski, J. SEIRAS studies of water structure at the gold electrode surface in the presence of supported lipid bilayer. J. Electroanal. Chem. 2014, 716, 112-119. [CrossRef]

61. Lafleur, M.; Pigeon, M.; Pezolet, M.; Caille, J.P. Raman spectrum of interstitial water in biological systems. J. Phys. Chem. A 1989, 93, 1522-1526. [CrossRef]

Sample Availability: Samples of the phytoglycogen extracts are available from Marcio Resende upon request (mresende@ufl.edu) from the authors.

(C) 2020 by the authors. Licensee MDPI, Basel, Switzerland. This article is an open access article distributed under the terms and conditions of the Creative Commons Attribution (CC BY) license (http://creativecommons.org/licenses/by/4.0/). 